\title{
Accountable Care Organizations Serving Deprived Communities Are Less Likely to Share in Savings
}

\author{
Alex R. Webb, BS, Winston Liaw, MD, MPH, YoonKyung Chung, PhD, \\ Stephen Petterson, PhD, and Andrew Bazemore, MD, MPH
}

Purpose: Primary care physicians are increasingly participating in accountable care organizations (ACOs). While prior studies have identified ACO and patient characteristics associated with savings, none have examined characteristics of the communities served by ACOs. Our objective was to assess the relationship between an ACO's service area characteristics and its savings rate.

Methods: In this cross-sectional study, we used the Centers for Medicare and Medicaid Services 2014 Medicare Shared Savings Program ACO Provider and Beneficiary, and Public Use Files to identify ACo and beneficiary characteristics. We used the American Community Survey to measure community deprivation at the ACO service area-level by using the social deprivation index. The outcome of interest was the ACO savings rate. We conducted bivariate analyses and regressions, adjusting for ACO organization and beneficiary characteristics.

Results: Our sample consisted of 320 ACOs participating in the Shared Savings Plan. The savings rate for ACOs serving the most deprived communities was $1.19 \%$ compared with $1.14 \%$ for those serving the least deprived. Adjusting for ACO and beneficiary characteristics, however, ACOs serving the most deprived had a savings rate that was 2.3 percentage points lower than those serving the least deprived.

Conclusions: ACOs serving deprived communities generate less savings. These findings are important to primary care practices, payers, and policy makers anticipating continued ACO expansion, if population health is to be achieved equitably. (J Am Board Fam Med 2019;32:913-922.)

Keywords: Accountable Care Organizations, Centers for Medicare and Medicaid Services (U.S.), Cross-Sectional Studies, Geographic Health Care Financing, Health Equity, Health Information Systems, Insurance, Medical Geography, Population Health, Primary Care Physicians, Primary Health Care, Surveys and Questionnaires

A central driver of the transition from volume to value has been the Centers for Medicare and Medicaid Services (CMS) and, specifically, its Accountable Care Organization (ACO) program. ACOs are coordinated groups of health care providers en-

This article was externally peer reviewed.

Submitted 4 January 2019; revised 1 May 2019; accepted 3 May 2019.

From the Georgetown University School of Medicine, Washington, DC (ARW); University of Houston College of Medicine Department of Health Systems and Population Health Sciences, Houston, TX (WL); Robert Graham Center Washington, DC (YKC, SP); American Board of Family Medicine, Lexington, KY (AB).

Funding: none.

Conflict of interest: none declared.

Prior presentations: 2017 North American Primary Care Research Group Annual Meeting in Montreal, Canada.

Corresponding author: Alex R. Webb, BS, 3900 Reservoir Road NW, Washington, DC 20007 (E-mail: Arw96@ georgetown.edu). gaged in alternate payment schemes that link cost and quality of care to reimbursement. When they reduce spending below a Minimum Savings Rate (MSR) while meeting quality standards they receive a percentage of the savings. Evaluations of the first years of the program reveal positive results, particularly for those that are physician owned and primary care based. ${ }^{1,2}$ As of 2016, CMS reports that ACOs have generated more than $\$ 1.29$ billion of savings $\left(0.2 \%\right.$ of total Medicare spending), ${ }^{3,4}$ and cover more than 9 million beneficiaries in Medicare Shared Savings Program (MSSP) ACOs alone. Year-to-year changes underscore the potential for greater savings. ${ }^{3,5}$ This has occurred despite attrition and mixed financial performance, highlighting the need for a more nuanced understanding of the drivers of ACO success. ${ }^{6}$ The continuing success of the ACO experiment requires richer evaluations of 
the underlying factors and their dissemination among practices, health systems, to ensure that benefits are equitably distributed.

There are many levels on which to explore ACO success, including individual, organizational, community, and regional characteristics. Recent studies have drawn attention to the association between success and organizational characteristics such as structure and practice patterns, ${ }^{7-10}$ while others have linked savings to beneficiary-level demographics. ${ }^{11-13}$ Lewis et $\mathrm{al}^{14}$ also showed that ACOs tend to form in relatively resource-rich areas, potentially widening existing disparities. This finding has been replicated at the physician level and across other CMS payment models like Comprehensive Primary Care Plus. ${ }^{15}$ Although a third of primary care physicians (PCPs) work in ACOs, participation is lower in places with vulnerable populations. ${ }^{16}$ These studies have identified important patterns among ACOs, though none have mapped ACO success against the contextual, communitylevel characteristics of their respective service areas.

While area-level social determinants influence health, researchers have yet to account for them in ACO models. ${ }^{17-19}$ Given their impact, it is critical to understand how these community factors affect ACO performance. If, for example, ACOs serving lower resource communities systematically underperform, practices in these areas will neither participate in ACOs nor share in their benefits, thereby widening health disparities. ${ }^{11,13,14}$ Our study seeks to address this question by exploring to what extent contextual service area characteristics are associated with ACO savings.

\section{Study Data and Methods}

This study examines whether ACO service area community characteristics, as measured by the social deprivation index (SDI; further described below under ACO Service Area Measures), are associated with savings among MSSP ACOs in 2014.

\section{Data}

In 2014, 333 ACOs participated in the MSSP, covering 5.3 million fee-for-service (FFS) beneficiaries. The participating ACOs were identified using data from the 2014 shared savings program (SSP) ACO Provider File. Their performance year (PY) assigned beneficiaries were linked using the 2014 shared savings program (SSP) ACO Beneficiary
File. The main outcomes and ACO characteristics were from the 2014 MSSP ACO Public Use File. Service area was determined using beneficiary ZIP codes from the 2014 Medicare Master Beneficiary Summary File. As they were not publicly available, beneficiary data were purchased and only available for 2014 ACOs.

Information regarding ACO service area community characteristics was obtained from the American Community Survey (ACS) 2008 to 2012 5-Year ZIP Code Tabulation Area (ZCTA) -level estimates. The Health Resources and Service Administration-Uniform Data System Mapper's 2013 ZIP-Code to ZCTA Crosswalk was used to link beneficiaries' residence 5-digit ZIP codes to their ZCTA-level neighborhood characteristics in ACS.

\section{ACO Service Area Measures}

We defined an ACO's service area to be the ZCTAs where $70 \%$ of its Medicare FFS beneficiaries reside. Specifically, we mapped beneficiary ZIP codes to ZCTAs, calculated the number of beneficiaries per ZCTA, rank ordered those ZCTAs from most to least, and then identified those ZCTAs comprising $70 \%$ of beneficiaries in the ACO (Supplemental Figure 1). ${ }^{20,21}$ The average number of ZCTAs in the $70 \%$ service area was 32 . A sensitivity analysis was performed using a range of thresholds for the service area to test the robustness of the results. Service area ZCTAs did not have to be contiguous.

Since our aim was to examine whether ACO savings varied across deprived and nondeprived communities, we were interested in the overall socioeconomic status (SES) of the service area rather than individual components. Hence, we used the SDI measure proposed by Butler et al. ${ }^{22}$ SDI is a measure of social and material deprivation, constructed by combining a variety of established publicly available socioeconomic measures into a composite measure using a latent variable approach. Specifically, first, each of seven American Community Survey ZCTA-level socioeconomic community characteristics-percent of households with income less than $100 \%$ federal poverty line, dwellings units where the number of inhabitants is greater than the number of rooms, households with no car, rental units, and single parent households, percent of those with less than 12 years of schooling, and percent of 18-64-year-olds who are nonemployed-are expressed in centiles across ZCTAs. Then, factor analysis weighted by the ZCTA pop- 
Figure 1. The Sample Savings Rate distributions for the bottom (Least Deprived) and top (Most Deprived) Social Deprivation Index Quartile Accountable Care Organization groups in 2014.

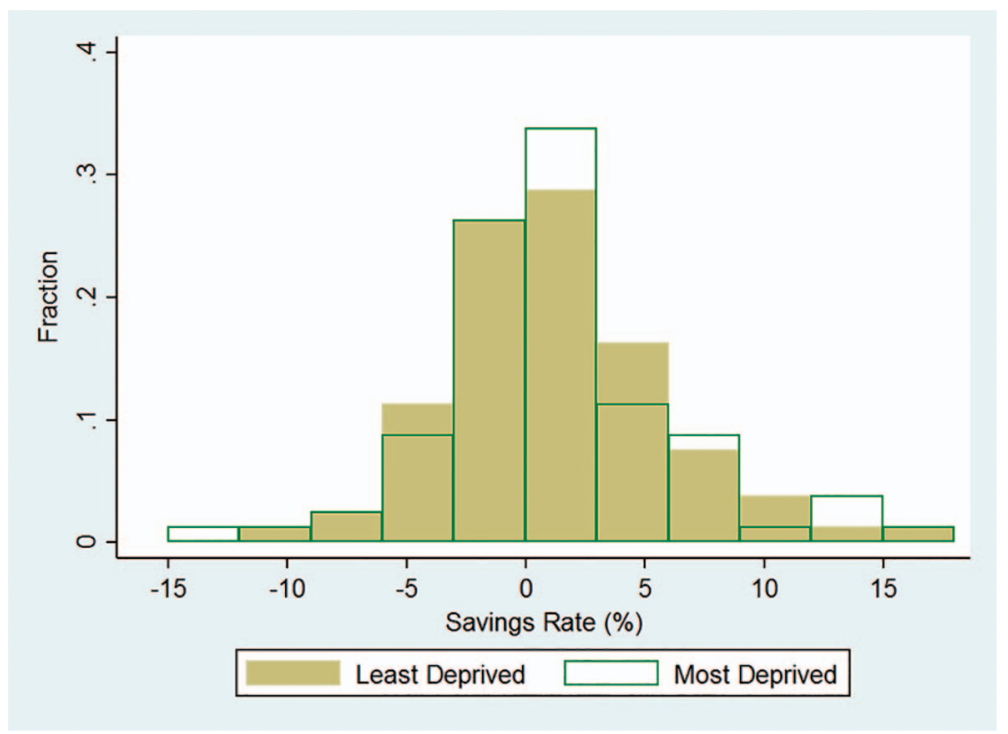

ulation size was performed on the above seven socioeconomic measures, then factor loadings from the analysis were used to construct the SDI. The paper also includes a more comprehensive version where two demographic factors-Black and highneed age group-are added, but since we are mainly interested in the socio-economic disadvantage of an area we selected the reduced version, in which the demographic factors were dropped due to lower factor loadings. Following their method, we created a ZCTA-level SDI using 7 service-area SES measures ranked in percentiles, then calculated the weighted average service area SDI for each ACO using beneficiaries per ZCTA as weights. The 7 ACS SES measures considered were percentage of adults 25 years and older who had less than high school education, with crowded housing, of households without a car, of adults under 65 years who were not employed, of households with income less than $100 \%$ federal poverty level, with renteroccupied housing, and of single-parent households. SDI is constructed such that it is standardized to mean of zero and standard deviation of 1 . A higher SDI indicates greater deprivation.

We then divided the ACOs into quartiles, by service area SDI. The top quartile (quartile 4 in the tables and figures below) represents ACOs that served on average the most deprived communities, whereas the bottom quartile, the least deprived (quartile 1 in the tables and figures below). Two ACOs in Puerto Rico were dropped since SDI was not available.

\section{Outcome}

The main outcome was the ACO shared savings rate. An ACO's savings rate was the difference between the total updated benchmark expenditures and the total expenditures of beneficiaries expressed as a percent of the former. The savings rate of our ACO sample ranged from $-13.4 \%$ to $16.0 \%$ (Figure 1). We also assessed whether the ACO shared in savings-a dichotomous variable. ACOs were eligible to share in savings if their savings rate was equal to or greater than the required ACOspecific MSR and their quality performance was satisfactory.

\section{Other Variables}

Other ACO organization and beneficiary characteristics included the number of beneficiaries, the year of program entry, ${ }^{23}$ share of ACO providers that were PCPs, and proportions of beneficiaries who were aged 85 years and older, female, white, aged dual eligibles, and disabled. Aged dual eligibles were 65 years and older Medicare beneficiaries who also qualified for Medicaid, and disabled were under age 65 years who received Social Security Disability Income.

We additionally adjusted for the ACO-specific per-capita historic benchmark expenditure in the analysis, since it is easier to save for those that are historically inefficient (through higher benchmarks). We also included the weighted average of Centers for Medicare and Medicaid Services-Hier- 
archical Condition Category (CMS-HCC) riskscore across enrollment types, using the shares in enrollment type as weights, to take into account the average relative health status of the assigned population. The CMS-HCC risk scores were only used to adjust for the changes in the health mix of the assigned beneficiaries when updating the benchmarks in the PY.

The aged dual eligible variable represented the share of ACO beneficiaries that also qualify for Medicaid. We also added the PCP share variable to adjust for differences in team composition across ACOs. However, 11 ACOs had no information on the number of PCPs and were dropped from the sample.

\section{Analysis}

First, we looked at the differences in the savings rate distribution between the ACO group whose service area was in the bottom SDI quartile (least deprived) and the group whose service area was in the top SDI quartile (most deprived). Then, using $t$-tests, we compared mean observable characteristics of the 2 groups across organizational, beneficiary, and service-area levels (Figure 1).

To compare the differences in the savings rate across ACOs with varying SDI, we conducted ordinary least square (OLS) regression with ACO savings rate as the dependent variable and SDI quartile, ACO characteristics, and beneficiary characteristics as the independent variables. In addition, we ran a sensitivity analysis using each component of SDI independently to examine which socioeconomic factors may be driving the results (Supplemental Figure 2).

We also examined whether the probability of ACO having shared in savings changes with the service area's SDI using a logistic regression model. The estimated coefficients of the SDI quartiles are expressed in odds ratios, showing the differences in the odds of sharing in savings relative to the top quartile group-those ACOs serving on average the most deprived communities.

This protocol was approved by the Institutional Review Board of the American Academy of Family Physicians.

\section{Results}

Our final sample consisted of 320 ACOs that participated in the 2014 MSSP, covering 5.2 million
Medicare FFS beneficiaries. Two hundred thirtynine of these ACOs did not share in savings almost entirely $(233 ; 97 \%)$ due to cost, where their actual savings rate was less than the target savings rate set by CMS.

\section{ACO Characteristics by SDI}

The distribution of savings rate varied across ACOs in PY 2014 (Figure 1) and differed between those whose service areas were in the most deprived quartile for SDI and those in the least. Compared with the "least-deprived" quartile, the distribution of the "most-deprived" quartile group demonstrated relatively more ACOs with extreme savings rates. ACOs in the most deprived quartile had a slightly higher average savings rate $(1.19 \%$ vs $1.14 \%)$.

There were significant differences in mean observable characteristics between the ACOs that on average served the most- (quartile 4) and least(quartile 1) deprived communities (Table 1). With regard to organization characteristics, those ACOs that served the most-deprived communities were on average more likely to be smaller, located in the South, and have a higher per-capita benchmark. However, there were no statistical differences either in the ACO's year of program entry or in team composition as measured by the share of PCPs. In addition, ACOs serving the most-deprived areas had higher percentages of beneficiaries who were dual eligibles, nonwhite, and disabled. Their beneficiaries also had a higher weighted average CMSHCC risk score.

As expected, service areas in the most-deprived SDI quartile fared worse in all components of SDI. The average ACO service area in the most- (least-) deprived SDI quartile had $19.5 \%$ (8.5\%) of adults with less than a high-school education, $19.9 \%$ $(8.7 \%)$ of the households living under the federal poverty level, $4.9 \%$ (1.7\%) of the housing units that were too crowded, and $39.9 \%(26.0 \%)$ in rental units, $12.9 \%(5.9 \%)$ of the households that do not own a vehicle, and $21.4 \%$ (13.9\%) in single-parent households.

\section{Regression Results}

Our main OLS regression results indicate that ACOs serving the least-deprived areas had a savings rate that was 2.3 percentage points higher than those serving the most-deprived areas (Table 2). Our sensitivity analysis demonstrates that the re- 
Table 1. Comparison of Characteristics Between Accountable Care Organizations Serving the Least to Most Deprived Communities in 2014

\begin{tabular}{|c|c|c|c|c|c|}
\hline & $\begin{array}{c}\text { Quartile 1 } \\
\text { (Least Deprived } \\
\text { Service Area), } \\
\text { Mean (SD) }\end{array}$ & $\begin{array}{l}\text { Quartile 2, } \\
\text { Mean (SD) }\end{array}$ & $\begin{array}{l}\text { Quartile 3, } \\
\text { Mean (SD) }\end{array}$ & $\begin{array}{c}\text { Quartile } 4 \\
\text { (Most Deprived } \\
\text { Service Area), } \\
\text { Mean (SD) }\end{array}$ & $\begin{array}{c}\text { Diff. (Q1-Q4), } \\
P \text { Value }\end{array}$ \\
\hline Savings rate $(\%)$ & $1.14(4.65)$ & $-0.18(4.46)$ & $-0.25(5.42)$ & $1.19(4.95)$ & \\
\hline Shared in savings & $0.31(0.47)$ & $0.23(0.42)$ & $0.25(0.44)$ & $0.23(0.42)$ & \\
\hline \multicolumn{6}{|l|}{ Organization characteristics } \\
\hline Number of assigned beneficiaries & $22,245(19518)$ & $18,552(17667)$ & $14,864(10962)$ & $9,714(6782)$ & $<.01$ \\
\hline \multicolumn{6}{|l|}{ Entry year } \\
\hline 2012 & $0.36(0.48)$ & $0.25(0.44)$ & $0.39(0.49)$ & $0.34(0.48)$ & \\
\hline 2013 & $0.31(0.47)$ & $0.36(0.48)$ & $0.3(0.46)$ & $0.24(0.43)$ & \\
\hline 2014 & $0.33(0.47)$ & $0.39(0.49)$ & $0.31(0.47)$ & $0.43(0.5)$ & \\
\hline \multicolumn{6}{|l|}{ Region } \\
\hline Northeast & $0.34(0.48)$ & $0.19(0.39)$ & $0.15(0.36)$ & $0.15(0.36)$ & $<.01$ \\
\hline Midwest & $0.23(0.42)$ & $0.23(0.42)$ & $0.28(0.45)$ & $0.10(0.3)$ & $<.05$ \\
\hline South & $0.33(0.47)$ & $0.4(0.49)$ & $0.44(0.5)$ & $0.58(0.5)$ & $<.01$ \\
\hline West & $0.11(0.32)$ & $0.19(0.39)$ & $0.14(0.35)$ & $0.18(0.38)$ & \\
\hline Track 2 & $0.00(0.00)$ & $0.00(0.00)$ & $0.01(0.11)$ & $0.03(0.16)$ & \\
\hline Per capita historical benchmark $(\$)$ & $10,172(2090)$ & $9,613(1801)$ & $10,741(2314)$ & $11,284(3145)$ & $<.01$ \\
\hline Quartile 1 & $0.25(0.44)$ & $0.36(0.48)$ & $0.18(0.38)$ & $0.21(0.41)$ & \\
\hline Quartile 2 & $0.24(0.43)$ & $0.30(0.46)$ & $0.26(0.44)$ & $0.20(0.40)$ & \\
\hline Quartile 3 & $0.33(0.47)$ & $0.21(0.41)$ & $0.26(0.44)$ & $0.20(0.40)$ & $<.1$ \\
\hline Quartile 4 & $0.19(0.39)$ & $0.13(0.33)$ & $0.30(0.46)$ & $0.39(0.49)$ & $<.01$ \\
\hline$\%$ Primary care physicians & $42.26(21.14)$ & $41.95(20.32)$ & $40.57(18.12)$ & $44.55(21.1)$ & \\
\hline \multicolumn{6}{|l|}{ Beneficiary characteristics } \\
\hline$\%$ Age 85 and older & $13.1(3.0)$ & $12.5(3.2)$ & $12.6(3.1)$ & $11.5(4.1)$ & $<.01$ \\
\hline$\%$ Female & $57.5(2.0)$ & $57.1(2.0)$ & $57.6(1.8)$ & $57.6(2.6)$ & \\
\hline$\%$ Aged duals & $4.0(2.8)$ & $5.0(4.0)$ & $6.3(3.3)$ & $16.4(15.2)$ & $<.01$ \\
\hline \% White & $88.3(8.2)$ & $88.9(6.8)$ & $83.8(11.1)$ & $67.8(21.6)$ & $<.01$ \\
\hline \% Disabled & $10.4(3.7)$ & $13.0(5.3)$ & $15.6(4.4)$ & $20.4(10.6)$ & $<.01$ \\
\hline HCC score & $1.0(0.1)$ & $1.0(0.1)$ & $1.1(0.1)$ & $1.1(0.1)$ & $<.05$ \\
\hline \multicolumn{6}{|l|}{ Service area characteristics } \\
\hline Number of ZCTAs & $32.2(19.4)$ & $32.7(22.6)$ & $27.4(24.3)$ & $33.9(29.7)$ & \\
\hline Social Deprivation index & $-0.70(0.21)$ & $-0.26(0.09)$ & $0.04(0.08)$ & $0.53(0.33)$ & $<.01$ \\
\hline$\%<12$ years of schooling & $8.5(1.9)$ & $10.9(1.9)$ & $13.6(2.1)$ & $19.5(6.6)$ & $<.01$ \\
\hline \% Crowded housing units & $1.7(0.8)$ & $2.1(1.1)$ & $2.4(1.3)$ & $4.9(3.5)$ & $<.01$ \\
\hline$\%$ Households with no care & $5.9(1.9)$ & $6.4(1.9)$ & $8.0(2.9)$ & $12.9(12.9)$ & $<.01$ \\
\hline$\%<100 \% \mathrm{FPL}$ & $8.7(2.4)$ & $12.5(2.0)$ & $14.6(2.1)$ & $19.9(5.6)$ & $<.01$ \\
\hline$\%$ Renter occupied & $26.0(5.2)$ & $31.3(5.0)$ & $33.2(5.0)$ & $39.9(10.5)$ & $<.01$ \\
\hline \% Single-parent households & $13.9(2.7)$ & $16.6(2.0)$ & $18.8(2.3)$ & $21.4(4.4)$ & $<.01$ \\
\hline $\mathrm{N}$ & 80 & 80 & 80 & 80 & \\
\hline
\end{tabular}

FPL, federal poverty level; HCC, Hierarchical Condition Category; SD, standard deviation; ZCTA, ZIP code tabulation area. Sources: Accountable Care Organizations (ACOs) were identified using the 2014 Shared Savings Program (SSP) ACO Provider File. Their beneficiaries were identified using the 2014 SSP Beneficiary File. The beneficiary ZIP codes were from the 2014 Master Beneficiary Summary File. ACO outcomes and characteristics were from the 2014 SSP ACO Public Use File. Service area characteristics were from the American Community Survey.

To generate the ACO service area, we summed the number of beneficiaries per ZIP code tabulation area (ZCTA), rank ordered those ZCTAs from most to least, and identified those ZCTAs comprising $70 \%$.

The social deprivation index (SDI) is a measure of social and material deprivation, constructed by combining a variety of established publicly available socioeconomic measures into a composite measure using a latent variable approach.

Hierarchical Condition Category (HCC) risk score is the weighted mean HCC risk scores across eligibility categories-disabled, end-stage renal disease (ESRD), aged and dual eligible, and aged and non-dual eligible. The mean HCC score for each eligibility category was normalized such that the national average score was 1 . For each ACO, we averaged across category-specific HCC scores using the assigned beneficiary share in that category as weights. 
Table 2. Associations Between 2014 Accountable Care Organization (ACO) Savings Rate and Beneficiary, ACO, and Service Area Characteristics

\begin{tabular}{|c|c|c|c|}
\hline \multicolumn{2}{|c|}{ Unadjusted } & \multicolumn{2}{|c|}{ Adjusted } \\
\hline Coeff. & CI & Coeff. & CI \\
\hline
\end{tabular}

Service Area Social Deprivation index

Quartile 1 (least deprived)

\begin{tabular}{rrrc}
\multicolumn{2}{c}{ Reference category } & \multicolumn{2}{c}{ Reference category } \\
-1.32 & {$[-2.74,0.10]$} & -1.06 & {$[-2.42,0.31]$} \\
-1.40 & {$[-2.97,0.18]$} & -2.68 & {$[-4.23,-1.14]$} \\
0.05 & {$[-1.44,1.55]$} & -2.29 & {$[-3.97,-0.61]$}
\end{tabular}

Quartile 2

Quartile 3

Quartile 4 (most deprived)

$[-1.44,1.55]$

$[-3.97,-0.61]$

Organization characteristics

Number of assigned beneficiaries

$$
\begin{aligned}
& <10,000 \\
& 10,000 \sim 29,999 \\
& \geq 30,000
\end{aligned}
$$

Entry Year

2012

2013

2014

Region

Northeast

Midwest

South

West

Track 2

Historical benchmark in quartiles

Quartile 1

Quartile 2

Quartile 3

Reference category

$$
\begin{array}{ll}
-1.12 & {[-2.41,0.18]} \\
-1.85 & {[-3.01,-0.69]}
\end{array}
$$

Quartile 4

$$
\begin{array}{rr}
\multicolumn{2}{c}{\text { Reference category }} \\
1.26 & {[-0.22,2.74]} \\
2.44 & {[0.76,4.12]} \\
-1.78 & {[-3.62,0.07]} \\
4.43 & {[2.29,6.58]}
\end{array}
$$

\% PCP

Reference category

Beneficiary characteristics

$\%$ Aged 85 and older

$\%$ Female

$\%$ White

0.03

$[-0.03,0.08]$

$\%$ Aged dual eligibles

0.05

$[-0.02,0.13]$

$\%$ Disabled

0.08

$[-0.01,0.17]$

HCC score

$\mathrm{N}$

320

CI, confidence interval; HCC, Hierarchical Condition Category; PCP, primary care physician.

Sources: Accountable Care Organizations (ACOs) were identified using the 2014 Shared Savings Program (SSP) ACO Provider File. Their beneficiaries were identified using the 2014 SSP Beneficiary File. The beneficiary ZIP codes were from the 2014 Master Beneficiary Summary File. ACO savings rate and characteristics were from the 2014 SSP ACO Public Use File. Service area characteristics were from the American Community Survey.

To generate the ACO service area, we summed the number of beneficiaries per ZIP code tabulation area (ZCTA), rank ordered those ZCTAs from most to least, and identified those ZCTAs comprising 70\%.

The social deprivation index (SDI) is a measure of social and material deprivation, constructed by combining a variety of established publicly available socioeconomic measures into a composite measure using a latent variable approach. We conducted regression where the savings rate was the dependent variable.

sults are robust to changes in the thresholds for the service area (available on request).

The results from separate OLS regressions show that a 1-SD increase in SDI was associated with a 1.17-percentage-point decrease in the savings rate
(Supplemental Figure 2). The estimates of most socioeconomic and demographic variables were generally consistent with that of the SDI. The results also imply that using each socioeconomic and demographic measure separately is likely to 
Figure 2. Ordinary Least Squares and Logistic Regression Results for Social Deprivation Index Quartiles.

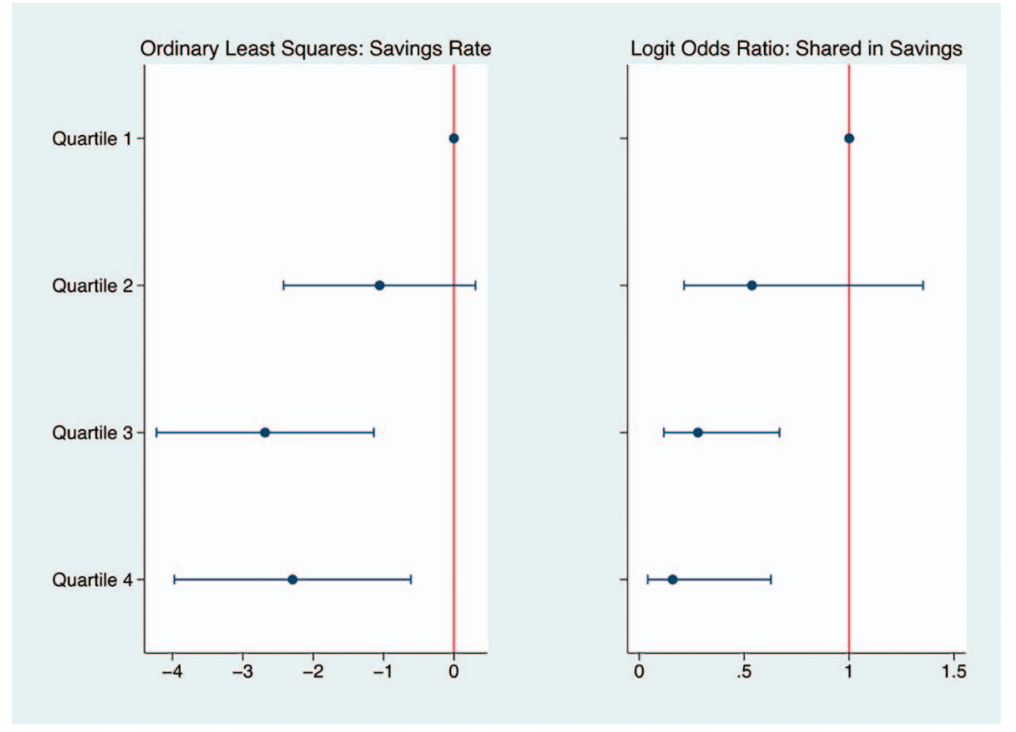

underestimate the association between providing care in deprived areas and savings.

We also noted that ACOs located in the South and the Midwest on average had a higher savings rate relative to those located in the Northeast. We confirmed findings from previous studies showing that early ACO participants on average had a relatively higher savings rates. ${ }^{23}$ ACOs' historic benchmark was strongly associated with savings: the adjusted mean difference in the savings rate between the highest and lowest benchmark quartile groups was 5.1 percentage points. Lastly, ACOs with a larger elderly population had a lower savings rate: a 1-percentage-point increase in the share of those who are 85 years and over was associated with a 0.26-percentage-point decrease in the savings rate.

The results from the logistic regression where receiving savings was the outcome (Figure 2) shows that those ACOs with a service area in the leastdeprived SDI quartile (Q1) were more likely to share in savings than those in the most-deprived SDI quartile (Q4). The odds of sharing in savings for those that served the least and second least deprived areas in the sample were 6.3 and 3.4 times, respectively, greater than those that served the most deprived. The OLS and logistic regression results exhibit a similar pattern of association between ACO savings and SDI quartiles: The more deprived the service area was the less likely to save.

\section{Discussion}

We found that ACOs in deprived communities were less likely to share in savings. Those in the least-deprived quartiles had 6.3-times-greater odds of sharing in savings than those in the most-deprived quartile. The adjusted average difference in savings rate between these 2 groups of ACOs (2.3 percentage points; Table 2) is greater than the MSR minimum of $2 \%$, meaning that this difference alone could convert an ACO from 1 that did not share in savings to one that did. These findings indicate that community profiles may be as significant in predicting an ACO's ability to save as the profiles of the beneficiaries themselves.

Ours is the first to link savings with service area characteristics, and these findings highlight an important gap. Previous research has shown that minorities and other vulnerable groups experience worse clinical outcomes, and that providers serving these populations are resource constrained. ${ }^{11,24-26}$ Individual SES has been linked with resource utilization, with low-SES patients requiring longer hospital stays. ${ }^{26}$ Despite disparities in readmissions and quality, ${ }^{11}$ ACOs serving a higher proportion of high-risk beneficiaries achieved savings at higher rates. ${ }^{27}$ These findings are consistent with the history of inefficient care for such high-risk beneficiaries: it is easier for an ACO to save with a higher per-beneficiary benchmark. ${ }^{8,28}$ When accounting for community service area level, however, the effect is inverted, 
and those ACOs serving the most at-risk communities actually find it the most difficult to save. These results have important implications for primary care as family physicians have been shown to be more likely than those in other specialties to work in physician-shortage and rural areas. ${ }^{29,30}$

The relationship between beneficiary and service area social risk factors and their apparent impact on savings reaffirms the importance of contextual, ecological effects on individual health outcomes, which seem potentially strong enough to impede ACOs' ability to save by targeting "lowhanging fruit." Jones et $\mathrm{al}^{18}$ have suggested a set of mechanisms through which geographical context can affect individual health, including the effects of physical environment, local culture, place deprivation, and selective mobility, ${ }^{18}$ and the link between these area-level risk factors and their impact on health outcomes has been well established. ${ }^{31-34}$ Concretely, this means that individuals in these deprived neighborhoods have poorer social, physical, and medical infrastructure compared with those in affluent areas. ${ }^{35} \mathrm{We}$ hypothesize that these beneficiaries have worse access to essential services such as transportation and medical care. These deficiencies, in turn, limit ACO savings. These mechanisms align with the conceptual framework built by the National Academy of Medicine in 2015 outlining the domains of social risk factors for potential inclusion in Medicare payment programs. $^{27,36}$

Our findings indicate the importance of considering the role of social context in health more broadly. The Department of Health and Human Services has explored methods for adjusting measurement and payment based on social risk factors, and our results can inform this debate. ${ }^{27}$ Although state-level differences between Medicaid coverage make interstate outcome comparisons imperfect, our findings show that nationally the current payment structure functions as a disincentive for ACOs to serve socially deprived communities. Failing to address this disincentive could widen health disparities. From a policy perspective, accounting for disparities in deprived areas will ensure that ACO savings accrue equitably by keeping participating providers and hospitals within these high need communities. ${ }^{24}$ Future studies should additionally characterize the current distribution of ACOs to determine whether it is already skewed away from socially deprived or otherwise at-risk communities.
Implicit in the argument for accounting for these factors is the ability to measure them. Given that the data necessary for SDI calculations is already collected nationwide and publicly available, our findings demonstrate this index's utility as a means for gauging community-level social risk. In all likelihood, these adjustments will need to be paired with multisectoral interventions like accountable health communities to ultimately improve the health of vulnerable populations. ${ }^{37,38}$

\section{Limitations}

There are several limitations to our analysis. First, this approach cannot separate the association between service-area characteristics and savings from that of ACO beneficiaries' individual characteristics. Since we were unable to measure income, job, housing, and education at the beneficiary level, we could not account for individual deprivation but believe that this would be a compelling future study. Second, we were unable to measure the strength of relationships between beneficiaries and ACOs. For example, we do not know whether or not beneficiaries perceive the providers and facilities within ACOs to be their usual sources of care. Third, our definition of ACO service area may not coincide with the ACO's actual service area. The ACO service area was calculated based on assigned FFS Medicare beneficiaries. This service area may change if we include Medicare Advantage, privately insured, and uninsured patients. We also did not account for the extent to which service areas overlapped, total land area covered, or population density. Fourth, our results may have changed if we used a different marker of community deprivation rather than SDI, as well as other methods of characterizing ACO service areas including racial composition. Fifth, we only used 1 year of data (2014). Current MSSP and Next-Generation ACOs incorporate regional benchmarks, which may affect our findings. ${ }^{40}$ Finally, we were unable to incorporate more granular information about ACOs, such as payer mix and electronic health record capabilities, that may affect the ACO's ability to provide coordinated care to the patients. While surveys have captured these data, they are not publicly available. ${ }^{41}$

\section{Conclusion}

In summary, ACOs serving deprived communities are less likely to generate savings. Our results have 
important implications for the distribution of ACOs, primary care participation, communities served by ACOs, and health equity. This relationship should be tracked over time and across ACO programs.

To see this article online, please go to: http://jabfm.org/content/ 32/6/913.full.

\section{References}

1. Jabbarpour Y, Coffman M, Habib A, et al. Advanced primary care: a key contributor to successful ACOs. Washington, DC: Patient-Centered Primary Care Collaborative; 2018.

2. McWilliams JM, Hatfield LA, Landon BE, Hamed P, Chernew ME. Medicare spending after 3 years of the Medicare Shared Savings Program. N Engl J Med. 2018;379:1139-1149.

3. Centers for Medicare \& Medicaid Services. Physicians and Health Care Providers Continue to Improve Quality of Care, Lower Costs. August 25, 2016. Available from: https://www.cms.gov/Newsroom/ MediaReleaseDatabase/Press-releases/2016-Pressreleases-items/2016-08-25.html. Accessed August 5, 2018.

4. Centers for Medicare \& Medicaid Services. National Health Expenditure Data. Published December 6, 2018. Available from: https://www.cms.gov/researchstatistics-data-and-systems/statistics-trends-and-reports/ nationalhealthexpenddata/nhe-fact-sheet.html. Accessed December 13, 2018.

5. McWilliams JM. Savings from ACOs-Building on early success. Ann Intern Med 2016;165:873-875.

6. Centers for Medicare \& Medicaid Services. Medicare Accountable Care Organizations: 2015 Performance Year Quality and Financial Results. August 25, 2016. Available from: https:/www.cms.gov/ Newsroom/MediaReleaseDatabase/Fact-sheets/2016Fact-sheets-items/2016-08-25.html. Accessed May 16, 2018.

7. McWilliams JM, Chernew ME, Zaslavsky AM, Hamed P, Landon BE. Delivery system integration and health care spending and quality for Medicare beneficiaries. JAMA Intern Med 2013;173:14471456.

8. McWilliams JM, Hatfield LA, Chernew ME, Landon BE, Schwartz AL. Early performance of accountable care organizations in Medicare. N Engl J Med 2016;374:2357-2366.

9. D'Aunno T, Broffman L, Sparer M, Kumar SR. Factors that distinguish high-performing accountable care organizations in the Medicare Shared Savings Program. Health Serv Res 2018;53:120-137.

10. Ouayogodé MH, Colla CH, Lewis VA. Determinants of success in Shared Savings Programs: an analysis of ACO and market characteristics. Healthcare 2017;5:53-61.
11. Lewis VA, Fraze T, Fisher ES, Shortell SM, Colla $\mathrm{CH}$. ACOs serving high proportions of racial and ethnic minorities lag in quality performance. Health Aff (Millwood) 2017;36:57-66.

12. Song Z, Rose S, Chernew ME, Safran DG. Lowerversus higher-income populations in the alternative quality contract: improved quality and similar spending. Health Aff (Millwood) 2017;36:74-82.

13. Hartzman A, Rhodes K. Accountable care organizations and disparities. Health Aff (Millwood) 2017;36: 960-960.

14. Lewis VA, Colla CH, Carluzzo KL, Kler SE, Fisher ES. Accountable care organizations in the United States: market and demographic factors associated with formation. Health Serv Res 2013;48(6 Pt 1): $1840-1858$.

15. Fraze TK, Fisher ES, Tomaino MR, Peck KA, Meara E. Comparison of populations served in hospital service areas with and without comprehensive primary care plus medical homes. JAMA Netw Open 2018; 1:e182169.

16. Yasaitis LC, Pajerowski W, Polsky D, Werner RM. Physicians' participation In ACOs is lower in places with vulnerable populations than in more affluent communities. Health Aff (Millwood) 2016;35:13821390.

17. McGovern L, Miller G, Hughes-Cromwick P. The relative contribution of multiple determinants to health outcomes. Health Aff Health Policy Brief. August 21, 2014. Available from: https:/www.healthaffairs.org/do/10.1377/ hpb20140821.404487/full/.

18. Jones K, Duncan C. Individuals and their ecologies: analysing the geography of chronic illness within a multilevel modelling framework. Health Place 1995; 1:27-40.

19. Smith GD, Hart C, Watt G, Hole D, Hawthorne V. Individual social class, area-based deprivation, cardiovascular disease risk factors, and mortality: the Renfrew and Paisley Study. J Epidemiol Community Health 1998;52:399-405.

20. Mullan F, Phillips RL Jr, Kinman EL. Geographic retrofitting: a method of community definition in community-oriented primary care practices. Fam Med 2004;36:440-446.

21. Griffith JR. Quantitative techniques of hospital planning and control. Lexington, MA: Lexington Books; 1972.

22. Butler DC, Petterson S, Phillips RL, Bazemore AW. Measures of social deprivation that predict health care access and need within a rational area of primary care service delivery. Health Serv Res 2013;48(2 Pt 1):539-559.

23. McWilliams JM. Changes in Medicare shared savings program savings from 2013 to 2014. JAMA 2016;316:1711-1713.

24. Kind AJ, Jencks S, Brock J, et al. Neighborhood socioeconomic disadvantage and 30-day rehospitalization: a retrospective cohort study. Ann Intern Med 2014;161:765. 
25. Wen M, Christakis NA. Neighborhood Effects on posthospitalization mortality: a population-based cohort study of the elderly in Chicago. Health Serv Res 2005;40:1108-1127.

26. Epstein AM, Stern RS, Weissman JS. Do the poor cost more? A multihospital study of patients' socioeconomic status and use of hospital resources. N Engl J Med 1990;322:1122-1128.

27. Assistant Secretary for Planning and Evaluation. Social risk factors and performance under medicare's value-based purchasing programs. 2016. Available from: https://aspe.hhs.gov/system/files/pdf/253971/ ASPESESRTCfull.pdf.

28. McWilliams JM, Chernew ME, Landon BE, Schwartz AL. Performance differences in year 1 of pioneer accountable care organizations. N Engl J Med 2015;372:1927-1936.

29. Grumbach K. Who is caring for the underserved? A comparison of primary care physicians and nonphysician clinicians in California and Washington. Ann Fam Med 2003;1:97-104.

30. Petterson S, McNellis R, Klink K, Meyers D, Bazemore A. The state of primary care in the United States: a chartbook of facts and statistics. Washington, DC: Robert Graham Center; 2018.

31. Jokela M. Does neighbourhood deprivation cause poor health? Within-individual analysis of movers in a prospective cohort study. J Epidemiol Community Health 2015;69:899-904.

32. Hahn RA, Eaker ED, Barker ND, Teutsch SM, Sosniak WA, Krieger N. Poverty and death in the United States. Int J Health Serv Plan Adm Eval 1996;26:673-690.

33. Pearson AL, Bentham G, Day P, Kingham S. Associations between neighbourhood environmental characteristics and obesity and related behaviours among adult New Zealanders. BMC Public Health 2014;14:553.

34. Keita AD, Judd SE, Howard VJ, Carson AP, Ard JD, Fernandez JR. Associations of neighborhood area level deprivation with the metabolic syndrome and inflammation among middle- and older-age adults. BMC Public Health 2014;14:1319.

35. Mueller G, Berger K. Associations of neighborhood area level deprivation with the metabolic syndrome and inflammation among middle- and older- age adults. Diabet Med 2012;29:831-833.

36. Committee on Accounting for Socioeconomic Status in Medicare Payment Programs, Board on Population Health and Public Health Practice, Board on Health Care Services, Institute of Medicine, National Academies of Sciences, Engineering, and Medicine. Accounting for social risk factors in medicare payment: identifying social risk factors. Washington, DC: National Academies Press; 2016.

37. Mays GP, Mamaril CB, Timsina LR. Preventable death rates fell where communities expanded population health activities through multisector networks. Health Aff (Millwood) 2016;35:2005-2013.

38. Centers for Medicare \& Medicaid Services. Accountable Health Communities Model. May 3, 2018. Available from: https://innovation.cms.gov/initiatives/ ahcm/. Accessed May 16, 2018.

39. Centers for Medicare \& Medicaid Services. Next generation ACO model. May 7, 2018. Available from: https://cmmicoordinator.polldaddy.com/s/wasthis-helpful? iframe $=$ https $\% 3 \mathrm{~A} \% 2 \mathrm{~F} \% 2$ Finnovation. cms.gov\%2Finitiatives\%2FNext-Generation-ACOModel\%2F\&ft=1. Accessed May 16, 2018.

40. Centers for Medicare \& Medicaid Services. Final Medicare Shared Savings Program Rule (CMS1644-F). June 6, 2016. Available from: https://www. cms.gov/Newsroom/MediaReleaseDatabase/Factsheets/2016-Fact-sheets-items/2016-06-06.html. Accessed May 16, 2018.

41. Albright BB, Lewis VA, Ross JS, Colla CH. Preventive care quality of Medicare Accountable Care Organizations: associations of organizational characteristics with performance. Med Care 2016;54:326335. 